\title{
As Representacõos de uma Turma de Mlunos do Ensino Médio acerca do Processo \\ de Ensino e Aprendizagem de Língua Inglesa em uma Escola Pública
}

The Representations of a High School Student Group about the Process of Teaching and Learning English in a Public School

\section{Jane Aparecida FLORÊNCIO* Patrícia MARCUZZO**}

Resumo: O objetivo deste trabalho foi identificar as representações de um grupo de alunos do Ensino Médio acerca do processo de ensino e aprendizagem de Língua Inglesa em uma escola pública. As representações desses alunos foram delineadas a partir de dados coletados por meio de um questionário, o qual apresentava perguntas acerca das experiências de aprendizagem dos alunos com a Língua Inglesa dentro e fora de sala de aula. Os alunos sugerem mudanças na forma como a disciplina vem sendo ministrada na escola pública.

Palavras-chave: Experiências. Sala de aula. Questionário.

Abstract: The present work aimed at identifying the representations of a High School student group about the process of teaching and learning English in a public school. These representations were described from the data collected by means of a questionnaire, which consisted of questions about the students' learning experiences with the English Language inside and outside the classroom. The students suggest changes the way the English language has been taught at school.

* Mestranda do Curso de Pós-Graduação em Letras - Estudos Linguísticos da Universidade Federal de Santa Maria (UFSM) Contato: janeaparecidaf@gmail.com. ** Doutora em Letras (2011) pela Universidade Federal de Santa Maria. Professora Adjunto do Departamento de Letras Estrangeiras Modernas da Universidade Federal de Santa Maria. Contato: patimarcuzzo@yahoo.com.br. 
Key-words: Experiences. Classroom. Questionnaire.

\section{Introdução}

No passado, o ensino de inglês como língua estrangeira estava voltado para o aprendizado da gramática e do vocabulário da Língua Inglesa (LITTLEWOOD, 2004) ${ }^{1}$. No entanto, pesquisas no campo da Linguística Aplicada levaram a uma conceituação mais ampla sobre as habilidades que os alunos de inglês como língua estrangeira precisam desenvolver (LITTLEWOOD, 2004). A partir dos resultados dessas pesquisas, o objetivo do ensino de inglês como língua estrangeira inclui vários aspectos voltados para o desenvolvimento de uma competência comunicativa, nos termos de Hymes (1972), incluindo as competências linguística, discursiva, pragmática, sociolinguística e sociocultural.

No entanto, apesar dos avanços no campo da Linguística Aplicada, verifica-se que, em muitos casos, há falta de clareza acerca dos objetivos do ensino de línguas em pelo menos dois contextos: a escola e os cursos de línguas, embora sejam instituições com objetivos diferenciados (BRASIL, 2006).

Em vista dessa aparente falta de clareza acerca dos objetivos do ensino de línguas na escola, parece que esse contexto precisa ser investigado a fim de se tentar identificar algumas razões para tal e, a partir disso, sugerir alternativas de mudança.

De fato, no Brasil, a partir da década de 1990, tem se observado uma abertura para a pesquisa realizada dentro da escola, deixando esta de ser apenas um espaço de ensino e aprendizagem de línguas e passando a ser também um contexto efetivo de pesquisa (MOITA LOPES, 2001). Esse contexto pode ser investigado a partir das representações da própria comunidade escolar envolvida no processo de ensino e aprendizagem de línguas estrangeiras, como é o caso deste trabalho ${ }^{2}$, o qual se deteve na

\footnotetext{
1 As interpretações de textos em Língua Inglesa foram realizadas pelas autoras deste trabalho.

${ }^{2}$ Este trabalho foi aprovado pelo Comitê de Ética em pesquisa da UNIFRA sob o registro na CONEP no 1246 e no CEP/UNIFRA n $291-2009$.
} 
investigação das representações sociais ${ }^{3}$ de uma parcela de uma comunidade escolar. O objetivo deste trabalho foi o de identificar as representações dos alunos do Ensino Médio de uma escola da rede pública de Santa Maria, no Rio Grande do Sul, acerca do processo de ensino e aprendizagem de Língua Inglesa.

O presente trabalho está organizado em quatro seções, além desta Introdução. $\mathrm{Na}$ próxima seção, são apresentadas as Orientações Curriculares Nacionais (OCNs) e duas abordagens de ensino, uma de base comunicativa e outra com base em gêneros. A seção de Metodologia descreve o contexto pesquisado, os participantes investigados, o instrumento de coleta de dados e os procedimentos de coleta e análise de dados. A seção de Resultados e Discussão apresenta, categoriza e interpreta quantitativa e qualitativamente os dados obtidos. Por fim, nas Considerações Finais, são retomadas resumidamente as interpretações dos dados e apontadas algumas contribuições para o ensino e a aprendizagem da Língua Inglesa.

\section{Considerações sobre o Ensino de Língua Estrangeira no Brasil}

Há diferentes documentos que norteiam a educação brasileira. Dentre eles, as Orientações Curriculares Nacionais (OCNs), que foram desenvolvidas a partir da necessidade de se retomar a discussão proposta nos Parâmetros Curriculares Nacionais do Ensino Médio (PCNEM), aprofundar alguns pontos que mereciam esclarecimentos e sugerir alternativas didático-pedagógicas para o ensino, contribuindo para o diálogo entre professor e escola sobre a prática docente (BRASIL, 2006).

Em relação ao ensino de Línguas Estrangeiras no Brasil, as OCNs (BRASIL, 2006, p. 87, grifo do autor) buscam:

3 Para Moscovici, as representações sociais são um sistema de valores, ideias e práticas que possui duas funções: "convencionalizar os objetos, as pessoas ou os acontecimentos que encontram" e serem "prescritivas, isto é, elas se impõem sobre nós com uma força irresistível”, que é “a combinação de uma estrutura que está presente antes mesmo que nós comecemos a pensar e de uma tradição que decreta o que deve ser pensado”. (MOSCOVICI, 2007, p. 26 apud ASSIS BRASIL; MARCUZZO, 2009, p. 166). 
... retomar a reflexão sobre a função educacional do ensino de Línguas Estrangeiras no ensino médio e ressaltar a importância destas; reafirmar a relevância da noção de cidadania e discutir a prática dessa noção no ensino de Línguas Estrangeiras; discutir o problema da exclusão no ensino em face de valores globalizantes e o sentimento de inclusão freqüentemente aliado ao conhecimento de Línguas Estrangeiras; introduzir as teorias sobre a linguagem e as novas tecnologias (letramentos, multiletramentos, multimodalidade, hipertexto) e dar sugestões sobre a prática do ensino de Línguas Estrangeiras por meio dessas.

Uma das proposições feitas pelas OCNs (BRASIL, 2006) estabelece que o ensino de Línguas Estrangeiras para o Ensino Médio deve contemplar as habilidades de leitura, de prática escrita e de comunicação oral contextualizadas. Além disso, é ressaltado que esse trabalho pode ser feito a favor da inclusão social, considerando os objetivos linguísticos, instrumentais, culturais e educacionais (BRASIL, 2006). Dessa forma, esse ensino poderá contribuir para a formação de indivíduos, de cidadãos (BRASIL, 2006).

As OCNs (BRASIL, 2006), atendendo a um propósito educacional - o de desenvolver o senso de cidadania -, têm como proposta a junção do projeto de letramento e de inclusão digital e social. O projeto objetiva trabalhar a linguagem desenvolvendo os modos culturais de ver, descrever e explicar, pois o projeto de letramento está intimamente ligado a modos culturais de usar a linguagem (BRASIL, 2006). Atualmente, a definição de letramento está nas práticas sociais e individuais de leitura e de escrita (SOARES, 2002), uma vez que tais práticas envolvem um processo de socialização à escrita e de incorporação de certos modos culturais de fazer e de dizer (MATENCIO, 2009). Desse modo, o termo letramento está sendo utilizado para a referência aos vários usos da linguagem em práticas socioculturais contextualizadas (BRASIL, 2006). "Isso leva à superação do restrito conceito anterior de alfabetização" (BRASIL, 2006, p. 106, grifo do autor), que concebe a linguagem fora de seu contexto significativo, ou seja, a linguagem trabalhada fora de sua prática social (BRASIL, 2006).

A respeito das práticas de ensino contextualizadas, as OCNs seguem a abordagem de ensino comunicativo, que visa a "preparar os alunos para a comunicação em Língua Estrangeiras em contextos significativos" (BRASIL, 2006, p. 120). Almeida Filho (1998, p. 37 e 47) afirma que o ensino 
comunicativo propicia "experiências de aprender com conteúdos de significação e relevância para a prática e o uso da nova língua" para que estas sejam reconhecidas pelos alunos como experiências válidas de formação e de conhecimento intelectual.

Sendo o contexto de uso o ponto de partida para o ensino (BRASIL, 2006), pode-se pensar o ensino de linguagem por meio dos gêneros discursivos. Além disso, aprender com base em gêneros é "condição básica de inserção no mundo letrado" (BRASIL, 2006, p. 72). Estudar os gêneros do discurso é aprender a agir em gêneros de atividades discursivas, em que aprender implica integrar um sistema de significação; é compreender as relações entre gêneros, em termos da coordenação de ações de linguagem nas atividades de interação (MATENCIO, 2009).

O ensino comunicativo e o ensino com base em gêneros, mencionados nas OCNs (BRASIL, 2006), merecem maior ênfase neste trabalho e, portanto, serão apresentados com mais detalhes.

Em meados dos anos 70, surgiu um novo conceito no ensino de línguas, competência comunicativa, e esse conceito, cunhado por Hymes (1972), introduziu uma visão teórica da linguística que incorporou comunicação e cultura (RICHARDS; RODGERS, 2010). "A teoria de Hymes de competência comunicativa era uma definição do que um falante precisa saber a fim de ser comunicativamente competente em uma comunidade discursiva" (RICHARDS; RODGERS, 2010, p. 154-159).

Desde o fim do século XX, esse conceito tem recebido bastante atenção na Linguística Aplicada, conforme destaca Almeida Filho (1998, p. 39, grifo do autor), "O proscênio tem sido ocupado pela abordagem comunicativa”. Para o pesquisador, o ensino comunicativo é definido como

... aquele que organiza as experiências de aprender em termos de atividades relevantes/tarefas de real interesse e/ou necessidade do aluno para que ele se capacite a usar a língua-alvo para realizar ações de verdade na interação com outros falantes-usuários dessa língua. (ALMEIDA FILHO, 1998, p. 36).

Sendo assim, ser comunicativo, para Almeida Filho (1998), significa preocupar-se com o aluno enquanto sujeito e agente no processo de formação por meio da Língua Estrangeira, enfocando menos o ensinar e concentrando mais forças no que abre ao aluno a possibilidade de se reconhecer nas práticas daquilo que faz sentido para sua vida. 
Uma das bases teóricas que fornece uma perspectiva de como ensinar comunicativamente é o ensino com base em gêneros, que tem tido um crescente interesse tanto no Brasil quanto no exterior (MEURER; BONINI; MOTTA-ROTH, 2005).

Desde a década de noventa do século XX, no Brasil, as teorias de gênero são cada vez mais estudadas, principalmente na área da Linguística Aplicada voltada para o ensino de línguas estrangeira e materna (ROJO, 2005). Isso se deve, em grande parte, aos referenciais nacionais de ensino de línguas (PCNs de línguas portuguesa e estrangeiras), que explicitamente destacam o uso dos gêneros como objeto de ensino (ROJO, 2005).

Padilha Pinto (2005) destaca que, ao interagirem de forma escrita ou oral no contexto escolar, os alunos precisam entender como os vários gêneros discursivos podem lhes subsidiar recursos para apresentar a informação e interagir com os outros.

No entanto, de acordo com Figueiredo (2008), os professores de língua (materna ou estrangeira) normalmente se questionam sobre como trabalhar com textos em sala de aula. A autora destaca que um dos problemas apresentados por alunos e até mesmo por cidadãos médios quanto à compreensão e produção de textos talvez seja as limitações das teorias tradicionais sobre o assunto, teorias que pautam o processo de aprendizagem da leitura e escrita na escola. A partir de uma perspectiva discursiva crítica, Figueiredo (2008) propõe, então, a análise de diferentes textos. Esta pesquisadora apresenta, por sua vez, a proposta de Meurer (2002), em que "qualquer texto tem o poder construtivo tríplice", ou seja, é constituído de representações, relações e identidades. Então, o exame dessas três faces do discurso pode ser um método a ser usado na leitura e análise crítica dos gêneros (MEURER, 2002). Portanto,

... descrever e explicar gêneros textuais relativamente às representações, relações sociais e identidades neles embutidas poderá servir para evidenciar que, no discurso, e através dele, os indivíduos produzem, reproduzem, ou desafiam as estruturas e as práticas sociais onde se inserem. Uma abordagem crítica dessa natureza poderá ajudar a entender que representar o mundo de uma determinada maneira, construir e interpretar textos evidenciando determinadas relações e identidades constituem formas de ideologia. (MEURER, 2002, p. 28). 
Esse é, de fato, o trabalho do ensino de línguas, o de "equipar os/as aprendizes com ferramentas teóricas e analíticas capazes de fomentar uma visão mais crítica das práticas discursivas, permitindo-lhes interagir criticamente com os textos que consomem e produzem" (MEURER, 2002, p. 178). A escola é o mais significativo de todos os lugares de mobilidade social potencial, ou seja, em termos de linguagem, a educação escolar tem o potencial de inserir os alunos dentro de uma variedade muito ampla de gêneros, os quais apresentam uma variedade ampla de relações sociais (COPE; KALANTZIS, 1993).

Nesta seção, foram apresentadas as OCNs para o Ensino Médio cuja proposta enfoca o ensino voltado para comunicação (ensino comunicativo) e o ensino da linguagem com base em gêneros.

$\mathrm{Na}$ próxima seção, serão apresentados os procedimentos adotados neste estudo.

\section{Metodologia}

Esta pesquisa é de base quantitativa e qualitativa. Grosso modo, a metodologia de base qualitativa é aquela que utiliza técnicas como, por exemplo, entrevistas de repostas abertas e/ou dados naturalísticos (análise da conversação, análise do discurso da sala de aula, observação participante) (DAVIS, 1995).

O universo de pesquisa é constituído por uma turma de 28 alunos de terceiro ano do Ensino Médio de uma escola de Ensino Fundamental e Médio da rede pública estadual de Santa Maria, Rio Grande do Sul, que respondeu ao Questionário de pesquisa sobre preferências do aluno acerca da Lingua Inglesa (anexo 1), para levantamento das representações acerca do processo de ensino e aprendizagem da Língua Inglesa.

A aplicação dos questionários foi realizada em sala de aula, em horário regular de atividades escolares, no fim do mês de novembro de 2009. Após a aplicação dos questionários, passou-se para a leitura e análise destes.

A análise desenvolvida foi extraída dos dados obtidos a partir do cabeçalho, que solicitava algumas informações pessoais, e das seis perguntas do questionário. Esses dados foram tabulados, comparados e organizados em termos de ocorrência e frequência das respostas (quantificação das respostas), então, seguiu-se para a análise das representações dos alunos. 


\section{Resultados e Discussão}

A análise dos dados revelou que a Língua Inglesa está muito presente na vida dos alunos investigados, pois é utilizada por eles dentro e fora da sala de aula. A utilização da Língua Inglesa fora da sala de aula, de acordo com os alunos, atinge um nível satisfatório. No entanto, a aula de Língua Inglesa não atinge as expectativas dos alunos, que apontam alguns fatores que contribuem para esse resultado, por exemplo, a (des)motivação, a falta de interação professor-aluno e a carga horária da Língua Inglesa na grade curricular. Além disso, percebem-se fortes características da pedagogia tradicional no ambiente escolar investigado.

No entanto, algumas sugestões foram feitas pelos alunos investigados e estas podem servir de estratégias de ensino e, ao mesmo tempo, podem possibilitar a interação entre professor-aluno na busca pela aprendizagem da Língua Inglesa.

Em relação à faixa etária, as idades dos alunos variavam entre 17 e 20 anos. Desses alunos, 61\% têm 17 anos. Observar a faixa etária dos alunos se torna indispensável, visto que o foco de interesse e necessidades dos alunos varia conforme sua idade. Essa observação pode ajudar na preparação e elaboração das aulas de Língua Inglesa, uma vez que preparar atividades com base nas necessidades e nos interesses que a faixa etária exige pode contribuir para alunos mais motivados a aprender. As OCNs (BRASIL, 2006) postulam que uma mesma pessoa pode pertencer a uma determinada classe social, a uma determinada idade, etc. e, sendo assim, essa pessoa possui conjuntos de valores e crenças associados a cada um dos grupos aos quais pertence. Além disso, esses conjuntos de valores e crenças se manifestarão "de acordo com cada contexto pelo qual essa pessoa transita" (BRASIL, 2006, p. 102).

\subsection{Habilidades no ensino de Inglês}

No aspecto relativo às habilidades a serem desenvolvidas nas aulas de Língua Inglesa, de acordo com as OCNs (BRASIL, 2006), a sugestão é focalizar a leitura, a prática escrita e a comunicação oral contextualizadas no ensino de Línguas Estrangeiras no Ensino Médio. A partir disso, uma das perguntas do questionário investigava qual a opinião dos alunos em relação às habilidades, solicitando que estes apontassem qual habilidade, entre as 
alternativas escrevendo, falando, lendo ou ouvindo (compreensão oral), promove a aprendizagem da Língua Inglesa. Os alunos também deveriam apontar uma justificativa para essa resposta.

De acordo com a maioria dos alunos, aprende-se mais a Língua Inglesa quando os exercícios propostos em sala de aula contemplam a habilidade da escrita (30\%).

Os resultados mostram que a escrita é uma habilidade importante para a maioria dos alunos para se aprender a Língua Inglesa. Tal resultado também foi obtido por Bohn (1994), ao analisar a percepção de aprendizes de línguas estrangeiras sobre o processo de escrita, em que o grupo de alunos pesquisados acredita que a prática da escrita é importante para aprender uma língua estrangeira, além de ser uma boa atividade para se avaliar a competência linguística.

Entretanto, ao analisar as razões pelas quais esses alunos preferiram determinada habilidade, pôde-se perceber que há três distintas ocorrências: uma habilidade promove a aprendizagem de outra, as habilidades consideradas fáceis para se aprender a Língua Inglesa e a concepção do processo de ensino e aprendizagem adquirida pelos alunos ao longo de sua escolarização.

Os dados da primeira ocorrência, dos alunos A 3, 5 e 26 - que acreditam que uma habilidade pode promover a aprendizagem de outra -, apontam para uma visão de linearidade, em que uma habilidade é o início do aprendizado da Língua Inglesa. No entanto, "uma habilidade só reforça a outra; aprendemos a falar ao modelar o que ouvimos, e aprendemos a escrever ao examinar o que podemos ler" (BROWN, 2001, p. 234).

Assim a gente aprende a escrever e consequentemente depois a falar. (A3 ao escolher a habilidade de escrita)

A partir da escuta você começa a falar, depois a ler e por último a escrever. (A5 ao escolher a habilidade de compreensão oral)

Ouvindo porque você aprende a falar. (A26)

Outros dados oferecem uma visão classificatória das habilidades, em que estas são classificadas em fáceis e difíceis quanto à aprendizagem da Língua Inglesa. As respostas dos alunos A 4, 17, 20 e 27 ilustram essa afirmação: 
Falando é mais fácil de ter entendimento. (A4)

Porque é mais fácil de aprender, é mais fácil do que ouvindo. (A17 ao escolher as habilidades de escrita, fala e leitura.)

Para mim são as maneiras mais fáceis. (A20 ao escolher a leitura e compreensão oral)

Considero os métodos mais fáceis. (A27 ao escolher a escrita e a leitura)

Uma crítica acerca do ensino fragmentado e compartimentado é feita pelas OCNs (BRASIL, 2006). Um exemplo disso é o trabalho que classifica os textos em fáceis ou complexos para iniciantes, intermediários ou avançados nos estudos de Línguas Estrangeiras (BRASIL, 2006). As OCNs (2006), citando Morin (2000), defendem o conhecimento integrador, compreendido das partes para o todo e do todo para as partes.

Pôde-se observar que a percepção de quatro alunos sobre a aprendizagem da Língua Inglesa se constitui de que o conhecimento está pronto para ser apreendido:

Sempre gravei mais lendo e escrevendo. (A16)

Falando e sabendo o que estamos dizendo gravamos melhor. (A21) Pois escrevendo no meu entender parece que eu gravo mais as palavras em inglês [...]. (A22)

Porque eu gravo melhor as palavras. (A24 ao escolher a habilidade de escrita)

O uso do verbo gravar pelos alunos faz alusão de que o ensino e a aprendizagem acontecem por meio da "repetição/imitação de modelos pré-estabelecidos" (SANTOS, 1994), uma vez que essa palavra pode significar manter na mente ou memorizar (LAUROSSE, 2007, p. 511). É importante mencionar que esse procedimento, a repetição/imitação, na prática de ensino e aprendizagem de uma língua estrangeira, é uma técnica empregada em exercícios de mecanização para praticar sons ou sentenças da língua-alvo (SANTOS, 1994). A desvantagem desse procedimento é que a repetição/ imitação pode inculcar e repercutir na formação do perfil dos alunos ao longo de toda sua escolarização (SANTOS, 1994).

Esse procedimento, de base controladora e limitada, segundo Santos (1994), se constitui como um dos obstáculos no processo de aprendizagem de uma língua estrangeira. 
Uma solução poderia ser a reversão dessa concepção, de que a aprendizagem acontece por meio de gravação/memorização, para que os aprendizes sejam capazes de construir sentidos, sem uma interferência prévia de modelos estabelecidos (SANTOS, 1994), e concebam a linguagem e o processo de construção do conhecimento como abertos e dinâmicos.

\subsection{Temas e gêneros nas aulas de Inglês}

As experiências de pesquisas e de anos de ensino (COELHO, 2005; NOVAKOSKY, 2010) apontam que aproveitar as opiniões de alunos a fim de tentar promover motivação é uma estratégia que funciona. Sendo assim, uma das perguntas do questionário enfocou os assuntos de interesse em que os alunos deveriam citar qual assunto, entre eles, comida, esportes, família, filmes, jogos, música, namoro, natureza e povos, eles gostariam de discutir nas aulas de inglês.

$\mathrm{O}$ assunto de maior interesse dos alunos foi filmes (31\%). A música $(27 \%)$ veio logo em seguida, com uma pequena diferença de interesse. Os demais assuntos despertam menor interesse dos alunos, como o assunto "esportes", que teve $12 \%$ da preferência dos alunos.

Coelho (2005), em sua pesquisa com alunos de Ensinos Fundamental e Médio, relata que a maioria dos entrevistados acredita que as atividades lúdicas, como assistir a filmes, ouvir música e jogar, servem como meios para se aprender a Língua Inglesa.

Partindo da perspectiva dos alunos que, em geral, consideram as atividades com filmes e músicas uma oportunidade de aprender, aliada à premissa de que o uso significativo da língua pelo aluno o conduz à aprendizagem, pode-se considerar a elaboração de atividades baseadas nos interesses e nas necessidades dos alunos como ajuda na aquisição da Língua Inglesa.

Da mesma maneira, saber que gêneros os alunos gostam de ler em inglês se torna indispensável. Dos dados obtidos da pergunta que sondava que gêneros os alunos gostam de ler, têm-se: música (46\%); notícias (22\%); reportagens (20\%); manuais de instrução (6\%); horóscopo (4\%) e blogs $(2 \%)$.

As músicas fazem parte do gênero canção. O gênero canção, quanto à definição, de acordo com Costa (2005, p. 107, grifo do autor), "é um gênero híbrido, de caráter intersemiótico, pois é resultado da conjugação de 
dois tipos de linguagem, a verbal e a musical”. Assim, esse gênero assume uma tripla competência: a verbal, a musical, e a literomusical (a capacidade de articulação das duas linguagens) (COSTA, 2005).

É importante ressaltar que a preferência dos alunos por esse gênero pode estar diretamente relacionada ao entretenimento que ele proporciona. Com a internet, as letras das canções são facilmente acessadas, facilitando sua apreciação, uma vez que, por meio delas, pode-se entendê-las e cantá-las.

Outra pergunta abordou em quais práticas, na Língua Inglesa, os alunos participam independentemente do ambiente de sala de aula, o que facilita essa prática e em que medida eles participam.

A prática mais frequente de inglês fora da sala de aula é escutar músicas e cantá-las (52\%). No entanto, ler textos de jornais, revistas, sites da internet, etc., também é uma atividade bastante desempenhada pelos alunos (28\%). Os dados indicam que uma parcela dos alunos assiste a filmes em inglês sem o uso de legenda (11\%). Uma minoria comunica-se com amigos virtuais no MSN, Orkut e Twitter (7\%) e fala com seus amigos (2\%) em inglês.

Indiscutivelmente, para esses alunos, a música e o inglês formam uma boa combinação. Coelho (2005) descobriu, ao entrevistar alunos de Ensinos Fundamental e Médio, que muitos acham que o aprendizado da Língua Inglesa acontece fora da sala de aula. Segundo a autora (2005), assistir a filmes e ouvir músicas foram os meios que os alunos encontraram de estudar sozinhos.

Os resultados mencionados por Coelho (2005), assim como os resultados dos alunos aqui investigados, evocam um aspecto muito importante do processo de aprendizagem do aluno/aprendiz: o senso de autonomia ${ }^{4}$.

No entendimento de Ellis (1997), o grau de esforço que os aprendizes fazem para aprender uma língua é influenciado pelas atitudes e pelos estados de afetividade, os quais envolvem a motivação.

${ }^{4}$ Autonomia: um sistema sociocognitivo complexo, que se manifesta em diferentes graus de independência e controle sobre o próprio processo de aprendizagem, envolvendo capacidades, habilidades, atitudes, desejos, tomadas de decisão, escolhas, e avaliação tanto como aprendiz de língua ou como seu usuário, dentro ou fora da sala de aula. (PAIVA, 2006, p. 88-89). 
Ellis (1997) aponta a existência de um tipo de motivação que, para esta pesquisa, talvez justifique o interesse dos alunos investigados: a motivação intrínseca. Em resumo, a motivação intrínseca varia de um momento para o outro, dependendo do contexto ou da atividade de aprendizagem.

A maioria dos alunos investigados (46\%), por sua vez, ao participar de práticas sociais, na Língua Inglesa, fora de sala da aula, sentiu-se confortavelmente bem. Tal fato pode acontecer por estarem motivados intrinsecamente, pois, provavelmente, a atividade desperta diversão, desafio ou necessidades. De acordo com Brown (2001), os aprendizes executam uma atividade porque ela é divertida, interessante, útil ou desafiadora.

Esse desempenho satisfatório é atribuído, essencialmente, a um fator: o vocabulário (32\%). As demais indicações foram: expressões e gírias $(17 \%)$; assunto $(17 \%)$; fluência (15\%); conhecimento de aspectos gramaticais $(10 \%)$; estrutura do texto/filme (7\%); e outros $(2 \%)$.

De acordo com Vereza (1994, p. 121), na época da "era estruturalista", o vocabulário era negado pela maioria dos linguistas, por não ser considerado como parte sistemática da língua, a sintaxe. Mais recentemente, o interesse pelo vocabulário tem crescido. No entanto, o vocabulário ainda é parte secundária do processo de ensino e aprendizagem, uma vez que seu desenvolvimento geralmente acontece de acordo com as unidades já estabelecidas do livro didático. Vereza (1994, p. 121) afirma que "os itens do vocabulário são freqüentemente vistos como um conjunto de unidades idiossincráticas (peculiares), que se autocontêm, as quais são tratadas como elementos de um conjunto e não como parte de um sistema”.

Tal visão do desenvolvimento do vocabulário não deixa outra opção ao professor senão o papel de apresentar esses itens e tentar agrupá-los e classificá-los para que os alunos, então, possam compreender seu significado e memorizá-los por meio da exposição e de estratégias de prática (VEREZA, 1994).

Embora as unidades do livro didático apresentem um vocabulário já elaborado, este não pode ser visto isoladamente, mas sim agregado às inferências do contexto em si e do conhecimento do aluno para gerar entendimento (VEREZA, 1994).

\subsection{Autonomia dos alunos}

Para averiguar a participação dos alunos, foi elaborada uma pergunta que solicitava que avaliassem seu próprio envolvimento nas aulas. 
Foi possível identificar a insatisfação deles com suas aulas de inglês. Os alunos A 2, 6, 28, e 14 apontaram a falta de interesse pelas aulas, e isso pode ser comprovado na escolha lexical faço o que é pedido, faço só o necessário e faço estritamente o necessário.

Faço só o necessário. (A2)

Só escuto, faço o necessário. (A6)

Faço o que é pedido. (A28)

Participava mais no começo do ano e faço estritamente o necessário. (A14)

É possível perceber o desinteresse e a adoção de uma postura tradicional, uma vez que "faço o que é pedido", sob a perspectiva tradicional, significa fazer quando solicitado. Conforme constatado por Oliveira (2004), no cenário de sala de aula, a participação dos alunos demonstrou que seus movimentos de reação ocorreram em menor número e, segundo a autora, isso "demonstra que os alunos trazem consigo uma crença de que o papel do aluno é apenas responder quando solicitado pelo professor" (OLIVEIRA, 2004, p. 110).

Outros alunos (A 15, 17 e 4), além de desmotivados, criticam a forma como a aula vem sendo ministrada. O aluno A15 descreve sua aula: ... a aula consiste em resumos no quadro. Talvez, esse aluno, inconscientemente, saiba que o processo de ensino e aprendizagem no ambiente escolar deve levar o aluno à construção gradativa de saberes (BRASIL, 2006). Já o aluno A17 demonstra revolta: É lamentável, não participo [...]. Além disso, faz questão de ressaltar que a escola, definitivamente, não é o lugar em que se aprende a Língua Inglesa: [...] o inglês que sei, certamente, aprendi em casa. Já o aluno A4 aponta seu envolvimento como indiferente: $\mathrm{Na}$ medida do possivel é bom [...] e relata, negativamente, que as aulas enfocam o livro didático: [...] mas o livro poderia ser menos importante nas aulas. Relatos assim, de que os livros são o único material utilizado em sala de aula, também foram reportados por Novakoski (2010).

Muito fraco, a aula não me chama nenhuma atenção, porque a professora só passa resumo no quadro e mais nada. Não tem graça nenhuma tentar aprender inglês assim. (A15) 
É lamentável [...] não participo, o inglês que sei, certamente, aprendi em casa. (A17)

$\mathrm{Na}$ medida do possível é bom, mas o livro poderia ser menos importante nas aulas. (A4)

Em geral, os alunos apresentam fortes indícios de desmotivação. Esses indícios circulam entre a abordagem utilizada pelo professor e a frustração do que se espera aprender na sala de aula de Língua Inglesa. A saída desse conflito pode estar na tomada de iniciativa por parte do aluno, a autonomia para se aprender a Língua Inglesa. No entanto, para Moreira (1994), essa autonomia só é encontrada quando os professores ajudam os alunos a enfocar o processo de aprendizagem, ou seja, quando os alunos aprendem a aprender.

A motivação é um caminho para aguçar a autonomia dos alunos. De acordo com Brown (2001), a motivação está intrinsecamente ligada ao aprendiz, pois é dentro dele que se encontram os desejos, as necessidades e os interesses. Então, o desenvolvimento de atividades que despertem a motivação intrínseca do aluno pode promover a autonomia necessária para que ele comece, por si só, dentro e fora de sala de aula, a executar atividades que conduzam à aprendizagem.

\subsection{Sugestões oferecidas pelos alunos}

Se uma forma de ativar a autonomia dos alunos deve partir da ajuda dos professores, então cabe ao professor investigar quais sugestões os alunos têm a fazer para melhorar o aprendizado da Língua Inglesa no contexto escolar. A partir disso, uma das perguntas do questionário abordou sugestões feitas pelos alunos investigados.

No entendimento de Brown (2001), uma grande contribuição do professor para com seu aluno e para com todo o processo de aprendizagem é aquela que leva em consideração cuidadosamente os motivos intrínsecos dos alunos e, a partir disso, cria atividades de sala de aula que alimentem esses motivos. Com base na proposta de Brown (2001), serão analisadas as sugestões dos alunos e serão feitos comentários a respeito e, posteriormente, reflexões serão feitas sobre possíveis aplicações das sugestões.

O maior número de ocorrências acerca das sugestões recaiu sobre as músicas e os filmes. 
Olhar filmes com legenda em inglês. (A12)

Ler mais textos em inglês, vocabulário, trabalhar com músicas. (A24)

O uso da internet e músicas. (A6)

Usar textos que prendam a atenção do aluno como música, filmes e futebol. (A5)

Trazer filmes, músicas e assuntos da atualidade ligados ao nosso mundo. (A13)

Assistir a bastante filmes em inglês, mais leituras, escutar mais músicas, [...] (A10)

Filmes, músicas, [...] (A25)

Usar músicas, filmes, etc. cosias que façam parte do nosso cotidiano. (A28)

Filmes sem legenda ou com áudio em português e legenda em inglês, pois assim é melhor para aprender. (A4)

Os alunos investigados revelaram grande interesse pela música no decorrer da análise dos dados de toda a pesquisa.

A música pode ser um recurso para o ensino, uma vez que oferece uma variedade de possibilidades (trabalhos com a produção oral, a escrita, a leitura e a compreensão oral). Certamente, isso dependerá da maneira como o professor vai usá-la para que supra de forma mais adequada as suas necessidades e seus interesses (SOUZA; MEDEIROS, 1994). Souza e Medeiros (1994) relatam que, em uma pesquisa realizada em Natal, Rio Grande do Norte, sobre a possibilidade de usar música na sala de aula de Língua Inglesa, observou-se que a música é considerada um elemento motivador no processo de ensino e aprendizagem, ponto de referência para aspectos histórico-culturais e material de ajuda para o ensino e para o estudo de textos.

Filmes foi outra sugestão apontada pelos alunos desta pesquisa para melhorar o aprendizado da Língua Inglesa. Cita-se, aqui, uma pesquisa realizada na Universidade Federal de Minas Gerais, cujo objetivo era revelar as estratégias individuais que dois grupos de alunos empregavam para aprender a Língua Inglesa (PAIVA, 1994). Uma das estratégias mais usadas como fonte de insumo para aprender a língua era assistir a filmes, e 50\% desses alunos disseram frequentar o cinema ou assistir a filmes na TV. Portanto, é válido considerar a elaboração de atividades com filmes para incentivar o aprendizado dos alunos. 
Outra sugestão apontada pelos alunos se refere à atuação do professor:

O professor interagir com os alunos. (A19)

Realmente os professores têm que saber como ensinar os alunos. (A15)

A professora faz poucos trabalhos para aguçar nossa vontade e curiosidade. (A16)

Aulas com professor de alto nível. (A14)

Professor interagir mais com os alunos. (A22)

Os alunos A 19 e 22 solicitam a interação por parte do professor. O aluno A15 afirma que o professor não sabe ensinar. Já o aluno A16 relata que as atividades propostas não instigam os alunos a querer aprender, e ressalta que o professor é o responsável. O aluno A14 acredita que o professor não tem qualificação suficiente. Em face desse descontentamento, vê-se a necessidade de delinear pelo menos quatro pontos de vista acerca da profissão de professor, sendo estes: o papel centralizante do professor, o papel passivo do aluno, a falta de interação entre professor e aluno e a desqualificação da profissão de professor sob o ponto de vista da sociedade.

O primeiro ponto de vista acerca da profissão professor, que dificulta sua atuação, citando Nicolaides e Fernandes (2001), é que os professores apresentam certa resistência em abrir mão de seu papel centralizante na sala de aula. Talvez, por terem receio de perder a posição de detentores do conhecimento e de controladores no processo de ensino e aprendizagem, fato que impede a interação de aluno-professor em sala de aula.

O segundo ponto de vista apresenta a crença do aluno, que é o outro lado da interação. Segundo Nicolaides e Fernandes (2001, p. 237), “os alunos acreditam que cabe ao professor a determinação do que, do quando, do como, e do quanto estudar"; a eles cabe seguir passivamente as instruções. Analisando a resposta do aluno A16, o qual, de forma negativa, relata que o professor faz poucos trabalhos para agucar a vontade e a curiosidade dos alunos, parece possível detectar "a falta de cultura para o desenvolvimento de autonomia” desse aluno (NICOLAIDES; FERNANDES, 2001).

O terceiro aspecto é a falta de coexistência entre professor e aluno. Segundo Almeida Filho (1998), pode ocorrer que uma cultura de aprender à qual se prende um aluno para abordar uma Língua Estrangeira não seja compatível com a abordagem específica de ensinar de um professor. Esse 
desencontro poderia ser a fonte básica de problemas, resistências, dificuldades, de fracasso e desânimo no ensino e na aprendizagem da Língua Inglesa (ALMEIDA FILHO, 1998).

O último aspecto se refere ao sentimento de culpa agregado à profissão de professor, que surge da própria sociedade. Segundo Celani (2001), a profissão de professor é encarada pelo poder governamental como um emprego subsidiário, pouco rendoso, de pequenos ganhos avulsos. Além disso, parece que a profissão de ensinar línguas é invadida de todos os lados: qualquer um pode ser professor ou profissionais de outras áreas ou de nenhuma assumem o ensino.

Algumas mudanças na tentativa de reverter esse pensamento negativo que é atribuído ao professor estão sendo sugeridas. Por um lado, o profissional de Língua Estrangeira deve se ver como alguém que tem um compromisso com seu aluno, com a sociedade e consigo mesmo, buscando um processo de educação permanente, de produção de conhecimento centrado na sala de aula, inserido na prática (CELANI, 2001). De outro, não significa apenas buscar o aperfeiçoamento contínuo da capacitação do professor de línguas estrangeiras, mas também a conscientização da sociedade, dos políticos e da área de educação acerca do trabalho do professor (WEININGER, 2001).

Entre as sugestões dos alunos, algumas poucas solicitam a presença da gramática em sala de aula de Língua Inglesa. Os alunos A 9, 26 e 3 sugeriram trabalhos que envolvam as características das pedagogias tradicionais, como a aplicação de provas e o foco na forma.

\section{Provas orais. (A9)}

Textos que trabalhem em cima de vocabulário e análise morfológica. (A26)

Escrever mais, sabendo diferenciar os tempos. (A3)

Segundo Almeida Filho (1998, p. 57), “a noção centralizante da estrutura gramatical tem predominado no ensino de Línguas Estrangeiras", uma vez que a ênfase tem sido na norma gramatical. Os excertos retirados das respostas dos alunos A 9, 26 e 3 indicam que estes acreditam que a gramática deve ser o foco de estudo. No entanto, no entendimento das OCNs (BRASIL, 2006, p. 107), o ensino isolado da gramática, ou seja, aquele que "não tolera variações ou contextualizações, promovendo-se como sistema único, correto e abstrato”, passa a ser insustentável, uma vez que a 
linguagem e o conhecimento passaram a ser concebidos dentro de uma visão heterogênea, plural e complexa.

Para Almeida Filho (1998), essa noção centralizante da gramática pode ser justificada, uma vez que os alunos recorram às maneiras de aprender típicas de seu contexto social. Essa abordagem de aprender evolui no tempo e em forma de tradições. "Uma tradição informa normalmente de maneira naturalizada, subconsciente e implícita as maneiras pelas quais uma nova língua deve ser aprendida" (ALMEIDA FILHO, 1998, p. 13). Portanto, esses alunos que sugeriram foco na forma, provavelmente, seguem a aprendizagem de tradição, que é a gramatical. A partir dessa perspectiva, fica mais fácil entender por que os alunos fizeram sugestões nesse sentido.

Outra questão apresentada pelos alunos aborda "a desvalorização da Língua Inglesa”. O aluno A20 menciona que a Língua Inglesa deveria ser retirada do currículo em razão de sua carga horária restrita, uma hora/aula semanal. Esse aluno duvida da eficácia da aprendizagem da Língua Inglesa nesses termos.

Tirá-lo [o inglês] do currículo, pois o inglês ensinado na escola com uma carga horária de uma hora por semana não é nem um pouco eficiente. (A20)

Esse pensamento sobre a exclusão do inglês do currículo no contexto das escolas públicas brasileiras foi analisado por Moita Lopes (2001). O autor revela que é comum ouvir afirmações do tipo: "Já que ninguém aprende Línguas Estrangeiras na escola pública, o melhor que se faz é tirá-lo do currículo ou então o aluno da escola pública não precisa de saber Línguas Estrangeiras" (MOITA LOPES, 2001, p. 127).

A forma como essas afirmações foram colocadas causa um sentimento de desvalorização das línguas, no caso investigado, a da Língua Inglesa. A respeito disso, parece haver falta de entendimento acerca dos objetivos do ensino de línguas na escola e, possivelmente, isso influencie o pensamento de que estas devam ser retiradas da escola. "O valor educacional da aprendizagem de uma língua estrangeira vai muito além de meramente capacitar o aprendiz a usar uma determinada língua estrangeira para fins comunicativos" (MOITA LOPES, 2001, p. 92), ele deve trabalhar a favor da inclusão e da formação de indivíduos. Essa falta de conscientização acerca da necessidade de se aprender uma língua estrangeira impossibilita a atitude 
de reivindicar condições melhores para o ensino de línguas estrangeiras, e é nesse sentido que se faz necessário o processo de mobilização.

\section{Considerações Finais}

Esta pesquisa teve como objetivo identificar as representações dos alunos do Ensino Médio do contexto escolar de Santa Maria, Rio Grande do Sul, acerca do processo de ensino e aprendizagem de Língua Inglesa. O enfoque deste trabalho foi o contexto de sala de aula de Língua Inglesa sob o viés do aluno, uma vez que os dados fornecidos por eles caracterizam suas experiências de aprendizagem em relação à Língua Inglesa.

Os resultados desta pesquisa apontam que o papel do aluno ainda é desenvolvido de forma passiva, uma vez que sua participação acontece somente mediante a solicitação do professor. Pelo menos dois fatores parecem estar diretamente ligados a essa passividade dos alunos: o primeiro deles é a frustração obtida em relação às expectativas do que os alunos gostariam de aprender. O segundo fator está relacionado ao papel do professor em sala de aula.

Com relação às expectativas dos alunos sobre o ensino e a aprendizagem da Língua Inglesa, chama a atenção o grande interesse pelas músicas e pelos filmes, sinônimos de entretenimento. De acordo com a análise dos dados, os alunos se sentiriam mais motivados se as aulas de Língua Inglesa fossem contempladas com atividades envolvendo músicas e/ou filmes, o que, de certa forma, poderia despertar a autonomia dos alunos, uma vez que seus interesses estariam sendo atendidos. Fora de sala de aula, esses alunos, guiados pelos seus desejos e interesses, desenvolvem o senso de autonomia, uma vez que relataram ouvir músicas e cantá-las. Assim, sugere-se que, nesse contexto, sejam elaboradas atividades que explorem esses gêneros discursivos.

Por fim, ressalta-se a importância do desenvolvimento de pesquisas etnográficas na sala de aula como contribuição para a reflexão e de possíveis mudanças no processo de ensino e aprendizagem, uma vez que é conhecendo as experiências dos alunos que se pode entender suas crenças e promover um ensino que vá ao encontro das expectativas dos alunos e dos objetivos do professor, contemplando, assim, a abordagem de ensinar e de aprender numa perspectiva comunicativa. 
Anexo 1 - Questionário de pesquisa sobre preferências do aluno acerca da Língua Inglesa

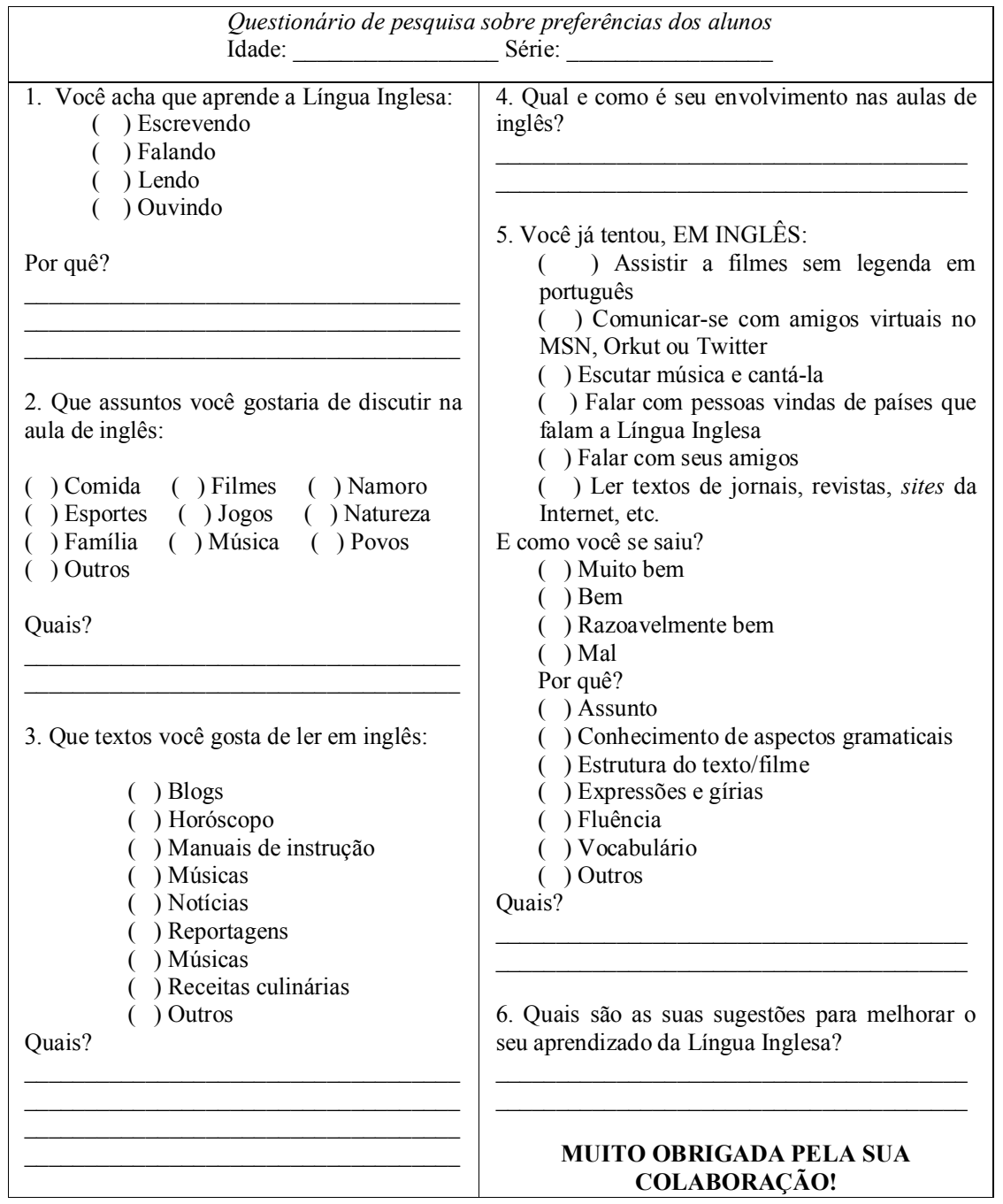




\section{Referências}

ALMEIDA FILHO, J. C. P. Dimensões comunicativas no ensino de linguas.

Campinas: Pontes, 1998.

ASSIS-BRASIL, A. M.; MARCUZZO, P. Um estudo sobre representações sociais de alunos de Letras sobre a produção escrita em Inglês. Expressão, Santa Maria, v. 1, p. 165-175, 2009.

$\mathrm{BOHN}, \mathrm{H}$. I. The perception of the composing process by Brazilian EFL learners. In: LEFFA, V. J. (Org.). Autonomy in language learning. Porto Alegre: UFRGS, 1994.

BRASIL. Ministério da Educação. Orientações curriculares nacionais para o Ensino Médio: linguagens, códigos e suas tecnologias. Brasília, DF: MEC, 2006.

BROWN, H. D. Teaching by principles: an interactive approach to language pedagogy. New Jersey: Engleawood Cliffs, 2001.

CELANI, M. A. A. Ensino de línguas estrangeiras: ocupação ou profissão? In: LEFFA, V. J. (Org.). O professor de Linguas Estrangeiras: construindo a profissão. Pelotas: Educat, 2001.

COELHO, H. S. H. "É possivel aprender inglês na escola?” Crenças de professores e alunos sobre o ensino de inglês em escolas públicas. 2005. Dissertação (Mestrado em Linguística Aplicada) - Universidade Federal de Minas Gerais, Belo Horizonte. 2005.

COPE, B.; KALANTZIS, M. The powers of literacy: a genre approach to teaching writing. Pittsburgh: Pittsburgh Press, 1993.

COSTA, N. B. As letras e a letra: o gênero canção na mídia literária. In: DIONISIO, A. P.; MACHADO, A. R.; BEZERRA, M. A. (Orgs.). Gêneros textuais e ensino. Rio de Janeiro: Lucerna, 2005.

DAVIS, K. Qualitative theory and methods in Applied Linguistics research. TESOL Quarterly, v. 29, n. 3, p. 427-453, 1995.

DICIONÁRIO ENCICLOPÉDICO ILUSTRADO LAROUSSE. São Paulo: Laurosse do Brasil, 2007. 
ELLIS, R. Second language acquisition. Oxford: Oxford University Press, 1997.

FIGUEIREDO, D. C. A Análise Crítica do Discurso na sala de aula: uma proposta de aplicação pedagógica. In: CALDAS-COULTHARD, C. R.; SCLIAR-CABRAL, L. (Org.). Desvendando discursos: conceitos básicos. Florianópolis: UFSC, 2008.

LITTLEWOOD, W. Second language learning. In: DAVIES, A.; ELDER, C. (Eds.). The handbook of applied linguistics. Malden: Blackwell Publishing, 2004.

MATENCIO, M. L. M. Estudos do letramento e formação de professores: retomadas, deslocamentos e impactos. Calidoscópio, v. 7, p. 510, 2009.

MEURER, J. L. Uma dimensão crítica do estudo de gêneros textuais. In: MEURER, J. L.; MOTTA-ROTH, D. (Orgs). Gêneros textuais. Bauru: EDUSC, 2002.

MEURER, J. L.; BONINI, A.; MOTTA-ROTH, D. (Orgs). Gêneros: teorias, métodos e debates. São Paulo: Parábola, 2005.

MOITA LOPES, L. P. Oficina de Linguística Aplicada: a natureza social e educacional dos professores de ensino/aprendizagem de línguas. São Paulo: Mercado de Letras, 2001.

MOREIRA, M. M. In the search of the foreign language learner's autonomy: concept maps and learning how to learn. In: LEFFA, V. J. (Org.). Autonomy in language learning. Porto Alegre: UFRGS, 1994.

MOSCOVICI, S. Representações sociais: investigações em psicologia social. 5. ed. Tradução P.A. Guareschi. Petrópolis: Vozes, 2007.

NICOLAIDES, C.; FERNANDES, V. A implementação de um centro de aprendizagem autônoma de línguas. In: LEFFA, V. J. (Org.). O professor de línguas estrangeiras: construindo a profissão. Pelotas: Educat, 2001.

NOVAKOSKI, S. F. University students' discussion on learning teaching experiences. 2010. Trabalho de Conclusão de Curso (Graduação em Letras) Universidade Federal de Santa Maria, Santa Maria. 2010. 
OLIVEIRA, S. B. Compreendendo o processo interacional na sala de aula de Lingua Inglesa: visões de professores e alunos. 2004. Dissertação (Mestrado em Linguística Aplicada) - Universidade Federal de Minas Gerais, Belo Horizonte. 2004.

PADILHA PINTO, A. Gêneros discursivos e ensino de língua inglesa. In: DIONISIO, A. P.; MACHADO, A. R.; BEZERRA, M. A. (Orgs.). Gêneros textuais e ensino. Rio de Janeiro: Lucerna, 2005.

PAIVA, V. L. M. Input Organization. In: LEFFA, V. J. (Org.). Autonomy in language learning. Porto Alegre: UFRGS, 1994.

PAIVA, V. L. M. Autonomia e complexidade. Linguagem \& Ensino, v. 9, p. 77-127, 2006.

RICHARDS, J. C.; RODGERS, T. S. Approaches and methods in language teaching. New York: Cambridge University Press, 2010.

ROJO, R. Gêneros do discurso e gêneros textuais: questões teóricas e aplicadas. In: MEURER, J. L; BONINI, A.; MOTTA-ROTH, D. (Orgs). Gêneros: teorias, métodos e debates. São Paulo: Parábola, 2005.

SANTOS, J. B. C. Os processos de aprender na sala de aula de língua estrangeira. In: LEFFA, V. J. (Org.). Autonomy in language learning. Porto Alegre: UFRGS, 1994.

SOARES, M. Letramento: um tema em três gêneros. Belo Horizonte: Autêntica, 2002.

SOUZA, M. B. D.; MEDEIROS, R. L. R. Motivating learners: using songs in the classroom. In: LEFFA, V. J. (Org.). Autonomy in language learning. Porto Alegre: UFRGS, 1994.

VEREZA, S. C. Vocabulary development: does it create independent learners? In: LEFFA, V. J. (Org.). Autonomy in language learning. Porto Alegre: UFRGS, 1994.

WEININGER, M. J. Do aquário ao mar aberto: mudanças no papel do professor e do aluno. In: LEFFA, V. J. (Org.). O professor de línguas estrangeiras: construindo a profissão. Pelotas: Educat, 2001. 